\author{
MI Restrepo \\ EM Mortensen \\ JA Pugh \\ A Anzueto
}

\section{DPOC associada a um aumento de mortalidade em doentes com pneumonia adquirida na comunidade}

\section{COPD is associated with increased mortality in patients with community-acquired pneumonia}

\section{Resumo}

A doença pulmonar obstrutiva crónica (DPOC) constitui, na actualidade, a quinta causa de morte, enquanto a pneumonia adquirida na comunidade (PAC) ocupa o sétimo lugar.

O objectivo do presente estudo foi demonstrar que a DPOC como comorbilidade representa um factor preditivo do aumento da mortalidade em doentes hospitalizados com PAC. Foi colocada a hipótese de que doentes com DPOC e PAC apresentavam uma taxa de mortalidade superior aos indivíduos sem a referida patologia crónica.

Trata-se de um estudo retrospectivo de doentes internados com PAC em dois hospitais universitários dos Estados Unidos da América.

Foram incluídos doentes admitidos entre 1 de Janeiro de 1999 e 1 de Dezembro de 2002 com o diagnóstico principal de pneumonia ou em que esta constituía uma intercorrência infecciosa em doentes com insuficiência respiratória ou sepsis como diagnóstico primário. Eram indivíduos com idade $\geq 18$ anos e diagnóstico de admissão de PAC apresentando uma radiografia do tórax ou tomografia axial computorizada efectuada nas primeiras 24 horas com achados consistentes com pneumonia.
Critérios de exclusão: Alta de uma unidade de cuidados intensivos nos 14 dias que precederam a admissão; transferência de outra entidade hospitalar; infecção VIH/SIDA. $\mathrm{Na}$ ausência da avaliação de função pulmonar, foram considerados como doentes com esta patologia crónica as referências no boletim de internamento a enfisema, bronquite crónica e DPOC. Esta é a estratégia utilizada na aplicação de regras preditivas e reflecte o método utilizado no índice de gravidade de pneumonia presente em múltiplos estudos.

Foram avaliadas a mortalidade aos 30 e 90 dias, o tempo de internamento, a admissão numa unidade de cuidados intensivos e a necessidade de ventilação mecânica. A mortalidade nos referidos períodos permite determinar a proporção de mortes atribuídas a pneumonia ou outras causas.

O diagnóstico definitivo foi baseado na presença de uma das seguintes condições: Hemoculturas positivas para agentes bacteriológicos ou fúngicos; cultura de líquido pleural positivo para agentes patogénicos; aspirado traqueobrônquico com elevado número de agentes bacteriológicos nocivos; crescimento significativo de estirpes agressivas em amostras obtido por broncofibroscopia ( $\geq 1 \times 10^{3}$ colónias $/ \mathrm{ml}$ ). 
O índice de gravidade da pneumonia foi utilizado para determinar a gravidade do quadro inaugural de pneumonia. Representa um factor preditivo de mortalidade aos 30 dias em doentes com PAC. Baseia-se em 3 características demográficas, 5 patologias associadas (comorbilidade), 5 achados do exame objectivo e 7 achados radiológicos ou laboratoriais no momento da admissão. Os doentes foram classificados em 5 classes, sendo o risco de mortalidade aos 30 dias de $0,1 \%$ na classe I e $27 \%$ na classe V.

Dos 744 doentes admitidos por PAC, 215 tinham o diagnóstico concomitante da DPOC, sendo $582(78 \%)$ homens e 162 (22\%) mulheres. A idade média era de $61 \pm 16$ anos (dos 18 aos 105). 83\% foram admitidos no serviço de emergência provenientes do domicílio e $7 \%$ de lares; $17 \%$ tinham sido submetidos a antibioterapia no domicílio.

Uma ou mais comorbilidades estavam presentes em $55 \%$ de doentes. As mais frequentes foram a insuficiência cardíaca congestiva (123 doentes) e o acidente vascular cerebral (105 indivíduos). Não existia patologia prévia em 15\% dos casos. A presença de PAC em doentes com DPOC foi mais frequente em idosos provenientes de um lar e admitidos numa unidade de cuidados intensivos nas primeiras 24 horas. A existência concomitante de DPOC e ICC ou doença neoplásica era comum. O exame objectivo e os achados laboratoriais e radiológicos demonstraram que os doentes com DPOC estavam, com maior frequência, taquipneicos, acidóticos e hipoxémicos.
A administração de antibióticos nas primeiras 4 horas ocorreu com maior incidência no grupo com DPOC (35 versus 26\%), tendo sido submetidos a menor número de exames diagnósticos (hemocultura pré-antibioterapia nas primeiras 24 horas 70 versus $77 \%$ ). Não se observou diferença significativa no nível de oxigenação entre os dois grupos.

O diagnóstico bacteriológico foi obtido em $23 \%$ dos doentes com agentes isolados em cultura do sangue e expectoração. A bacteriemia estava presente em 10\% dos doentes sem DPOC e 4,6\% dos indivíduos com esta patologia. Hemoculturas positivas em 8,5\%.

Os agentes mais frequentes foram o Streptococcus pneumoniae (56) e o Staphylococcus aureus (39 casos). Os doentes com PAC e DPOC apresentaram mais infecções por Pseudomonas aeruginosa e Haemophilus influenzae, mas menos por $S$. aureus do que os doentes sem DPOC. O tempo de internamento foi mais prolongado nos indivíduos com DPOC ( $9 \pm 25$ versus $7 \pm 8$ dias). A mortalidade global aos 30 e 90 dias foi de 10 e 14\%, respectivamente. Esta foi inferior no grupo sem DPOC: 30 dias $8,7 \%$ versus $10,6 \%$; 90 dias $-11,7 \%$ versus $18,6 \%$. O índice de gravidade da pneumonia foi mais elevado nos doentes com DPOC (105 \pm 32 versus $87 \pm 34)$, bem como a taxa de admissão numa unidade de cuidados intensivos (20\%), mas a necessidade de ventilação mecânica não. Verificou-se, também, que não houve diferença na mortalidade aos 30 e aos 90 dias nos doentes com PAC e DPOC admitidos numa UCI e sob ventilação mecânica ou que apresentavam bacteriemia.

\section{Comentário}

O presente estudo demonstrou que doentes com DPOC internados com PAC comparados com indivíduos sem a referida patologia apresentavam uma taxa de mortalidade aos 30 e aos 90 dias significativamente superior.
O primeiro grupo exibe uma maior taxa de admissão numa unidade de cuidados intensivos e um tempo de internamento mais prolongado. Estes dados confirmam que a DPOC deve ser considerada como indicador preditivo da gravidade da pneumonia. 
A DPOC tem sido encarada como um factor de risco de desenvolvimento de PAC, tendo múltiplos estudos revelado que constitui uma comorbilidade comum. No entanto, não tinha sido previamente classificada como um factor preditivo da mortalidade na PAC.

Houve diferenças significativas entre os indivíduos com e sem DPOC: O primeiro grupo apresentava uma idade mais avançada, maior número de admissões a partir de lares e requerendo cuidados intensivos nas primeiras 24 horas. Estavam mais taquipneicos, acidóticos e hipoxémicos. Todas estas variáveis estavam incluídas no índice de gravidade da pneumonia, o índice preditivo utilizado neste estudo. Este score inclui 5 situações de comorbilidade (doença cardiovascular, neoplasia, doença cerebrovascular, doença renal e hepática) não englobando, no entanto, a DPOC.

O presente estudo demonstra que os doentes com PAC e DPOC têm maior número de infecções atribuídas a Pseudomonas aeruginosa. Outros ensaios revelaram que este agente é uma poderosa estirpe patogénica em indivíduos com determinadas patologias pneumológicas, nomeadamente bronquiectasias.

Os dados evidenciaram que a $P$. aeruginosa constitui o segundo organismo mais frequente neste grupo. Desta forma, a cobertura antibiótica antipseudomonas deve ser considerada em doentes com DPOC, mesmo na ausência de bronquiectasias.

Este estudo possui, no entanto, limitações. A primeira resulta do facto de se tratar de um estudo retrospectivo, apesar de o diagnóstico radiológico da PAC ter sido confirmado em todas as situações. Outras limitações: Amostra predominantemente masculina; ausência de confirmação serológica; diagnóstico de DPOC baseado na história clínica. Não foi possível obter dados referentes a estudos funcionais respiratórios ou sobre a gravidade da DPOC. A avaliação funcional ajudaria a prever quais os doentes com DPOC que apresentariam maior morbilidade e mortalidade se desenvolvessem uma PAC.

Em conclusão, este trabalho evidencia uma mortalidade aos 30 e aos 90 dias, um tempo de internamento e uma taxa de admissão numa UCI mais elevadas no doente com DPOC internado por PAC, em comparação com doentes sem a patologia em causa. Estes achados têm influência na avaliação clínica de doentes com DPOC e PAC e na administração empírica de antibioterapia. Novos estudos prospectivos permitirão determinar o impacto da gravidade da DPOC e o uso de antibióticos antipseudomonas nos doentes com DPOC e PAC.

\section{Mensagem}

- Os doentes com DPOC internados por pneumonia adquirida na comunidade apresentam uma maior taxa de mortalidade aos 30 e aos 90 dias do que os indivíduos sem a referida patologia.

- O índice de gravidade da pneumonia, o tempo de internamento médio e a frequência de admissão numa unidade de cuidados intensivos são superiores no grupo com DPOC.

- A DPOC deve ser considerada um factor preditivo da mortalidade no doente com PAC.
A DPOC tem sido encarada como um factor de risco de desenvolvimento de PAC

(...) os doentes com PAC e DPOC têm maior número de infecções atribuídas a Pseudomonas aeruginosa 


\section{Bibliografia}

Farr BM, Sloman AJ, Fisch MJ. Predicting death in patients hospitalized for community-acquired pneumonia. Ann Intern Med 1991; 115: 428-36

Niederman NS, Mandell LA, Anzueto A et al. Guidelines for the management of adults with community-acquired pneumonia. Diagnosis, assessment of severity, an- timicrobial therapy and prevention. Am J Respir Crit Care Med 2001; 163: 1730-54

Ruiz M, Ewig S, Marcos MA et al. Etiology of community-acquired pneumonia: impact of age comorbidity and severiry. Am J Respir Crit Care Med 1999; 160: 397-405

Fátima Caeiro 07.03.07 